\title{
Los pimas del padre Kino ${ }^{1}$
}

\author{
Belén Navajas Josa \\ Universidad Francisco de Vitoria (Madrid) \\ b.navajas@ufv.es
}

Recibido: 16 de abril de 2011

Aceptado: 20 de julio de 2011

\section{RESUMEN}

El padre Kino fue el primer europeo que entró en contacto con los pimas. A través de sus escritos y los de los militares que recorrieron con él la Pimería -territorio incógnito en la frontera norte de Nueva España- a finales del siglo XVII y principios del siglo XVIII es posible obtener una serie de datos etnográficos relevantes para el estudio de este grupo, así como detalles sobre la metodología misionera y la vida cotidiana en un territorio de frontera.

Palabras clave: Pimería, pimas, apaches, jesuitas, aculturación, Padre Kino, capitán Juan Mateo Mange.

\section{Father Kino’s Pima}

\begin{abstract}
Father Kino was the first European to contact the Pima. It is possible to get some relevant ethnographical data of this group through his written works and those of the soldiers who accompanied him in his journeys through the Pimería -the unknown territory in the North borderlands of New Spain- along the end of the $17^{\text {th }}$ century and the beginning of the $18^{\text {th }}$ century. These works also provide details of the missionary methodology and the everyday life in the frontier.
\end{abstract}

Key words: Pimería, Pima, Apache, Jesuits, acculturation, Father Kino, Captain Juan Mateo Mange.

Sumario: 1. Introducción. 2. Los orígenes de los pimas. 3. La metodología de Kino. 4. Los compañeros del Kino. 5. Los pimas en la época de Kino. 6. Conclusiones. 7. Fuentes originales consultadas. 8. Referencias bibliográficas.

\section{Introducción}

El padre Kino llegó a la Pimería en 1687, una tierra incógnita que se extendía al norte de Sonora, en la frontera de Nueva España. El jesuita se asentó en el pueblo de Cosari, que bautizó con el nombre de Nuestra Señora de los Dolores, y a lo largo de veinticuatro años recorrió cientos de leguas y realizó más de cuarenta entradas o expediciones, fundando alrededor de veinticinco misiones.

La vocación de Kino había sido siempre la evangelización en tierras lejanas y así lo había comunicado al general Oliva en ocho cartas desde Alemania. Sin embargo, tuvo que esperar varios años a que su deseo se convirtiera en realidad. Finalmente, la autorización llegó en 1678 y el jesuita embarcó en Génova rumbo a España para des-

\footnotetext{
1 Este artículo es resultado de las investigaciones llevadas a cabo para la elaboración de una tesis doctoral, dirigida por la Dra. Emma Sánchez Montañés y el Dr. Francisco Javier Gómez Díez, presentada en el departamento de Historia de América II (Antropología de América) de la Facultad de Geografía e Historia de la Universidad Complutense de Madrid, en junio de 2008. Ver Navajas Josa 2009 y 2011.
} 
de allí cruzar el océano que le llevaría a su destino. Aunque su prioridad era misionar en Asia, tuvo que conformarse con un destino diferente: México.

Tras una escala en Alicante, la expedición jesuita de la que formaba parte Kino alcanzó las costas de Cádiz. Pero la travesía sufrió retrasos y no llegaron a tiempo de embarcar en la nave que debía conducirles a América. El grupo se instaló entonces en el Colegio Jesuita de Sevilla y allí comenzó un período de espera, que Kino supo aprovechar aprendiendo la lengua española y escribiendo Exposición astronómica del cometa, un tratado sobre el cometa que recorrió los cielos del sur de España en esos momentos. De este período se conservan varias cartas de la abundante correspondencia que el jesuita cruzó con la duquesa de Aveiro. Todavía esperaba que con la intercesión de la influyente dama su destino se dirigiera hacia Oriente. Finalmente, tras dos años de paciente espera, llegó el momento de embarcar, con la mala fortuna de que la nave sufrió un naufragio cerca de la costa, percance que todavía retrasó unos meses la salida definitiva que se produjo en enero de 1681. Y por fin, tres meses más tarde, Kino y sus compañeros desembarcaban en las costas mexicanas.

Una vez en la ciudad de México, sus conocimientos como cartógrafo y matemático le llevaron a ser elegido para participar en la expedición que el almirante Atondo preparaba a tierras californianas. Desde su descubrimiento en 1533 por Hernán Cortés, California había despertado el interés de los monarcas y sucesivas expediciones se habían dirigido hacia la península, terminando todas ellas en fracaso. La expedición Atondo alcanzó el puerto de La Paz en la costa californiana en marzo de 1683. Tras permanecer cuatro meses, se vieron obligados a regresar a México ante la falta de víveres, ya que la nave que debía aprovisionarles no consiguió llegar a causa de las inclemencias del tiempo. Pero Atondo y Kino no se rindieron y organizaron un segundo viaje. Nuevamente desembarcaron en California, esta vez más al norte, en San Bruno, el 6 de octubre de 1683, pero un año y medio después tuvieron que volver a abandonar por haber enfermado gran parte de los soldados que les acompañaban. El almirante y el jesuita formaban un buen equipo y lejos de desfallecer acometieron la organización de una tercera expedición, que nunca se llevó a cabo al retirarse los fondos. El rey Felipe $\mathrm{V}$ precisaba de todos los medios económicos para las numerosas guerras que desarrollaba en diferentes frentes en Europa.

A pesar del fracaso, la experiencia californiana fue clave en la trayectoria del jesuita. Siempre intentaría regresar a California, pues consideraba que su misión evangelizadora debía desarrollarse en aquellas tierras. Se había entusiasmado con California y con toda la labor que allí podía realizar. Ante él se extendía un vastísimo territorio habitado por naturales a los que transmitir la palabra de Dios. Además, su interés como cartógrafo se había despertado enormemente y se proponía aclarar si California era isla o península. Cuando Kino llegó a México, lo hizo con el convencimiento de su peninsularidad. Sin embargo, la creencia generalizada de que era isla, le llevó a rectificar y así en sus primeros mapas de la zona dibujó a California como isla. Tal es el caso de uno de sus principales mapas, ya posterior a su estancia californiana, el Teatro de los Trabajos de 1696. Pero no acababa de estar convencido, de modo que California se convirtió en su nuevo anhelo, como misionero y como cartógrafo, olvidando el Oriente de su juventud. El mapa Paso por tierra de 1701 es el primero exacto de la Pimería y durante más de un siglo fue el principal mapa que existió so- 
bre la región. Kino quiso con este trabajo dejar clara la peninsularidad de California. Pero como científico que era, hasta que no tuvo la certeza absoluta de su teoría, no la plasmó en un mapa, a pesar de que todavía años después, eran muchos los detractores de su idea.

Las órdenes de la Compañía de Jesús, sin embargo, nuevamente señalaron un destino contrario a sus deseos. En esta ocasión debía hacerse cargo del pueblo de Cosari en la Pimería. Y allí llegó el jesuita el 13 de marzo de 1687 acompañado de los padres José Aguilar y Manuel González. La compañía sólo duraría unas semanas, ya que ambos padres debían regresar a Oposura, la que hasta entonces había sido la más septentrional de las misiones de Sonora. Pero esta nueva situación no le arredró y, no contento con instalarse en el límite de tierras conocidas, comenzó un periplo que le llevaría a recorrer durante veinticuatro años esta tierra incógnita, adentrándose en un territorio que nunca antes había sido atravesado por ningún europeo. Ahora se le presentaba la ocasión de demostrar la peninsularidad de California. Su plan era ir fundando un rosario de misiones hacia el oeste de modo que pudiera alcanzar California a través del paso por tierra que debía descubrir y así comunicarse con el punto donde se había visto obligado a abandonarla.

\section{Los orígenes de los pimas}

No es fácil establecer los límites geográficos de la Pimería, dado precisamente su carácter fronterizo. Las fronteras se desplazaban hacia el norte pero también retrocedían. A grandes rasgos podemos establecer que limitaba al norte con el río Gila, al este con el río San Pedro, al sur con el río Magdalena y al oeste con el golfo de California y el río Colorado.

Se trata de un territorio árido, con lluvias escasas, pero con territorios fértiles en los márgenes de los ríos, lo que había originado una forma de vida sedentaria entre los indios pimas del río Gila, que vivían en rancherías y basaban su economía principalmente en la agricultura. En la zona más occidental, sin embargo, el desierto y la ausencia de ríos había llevado a sus habitantes, los pápagos, a desarrollar una vida seminómada. En los períodos de lluvias, en verano, practicaban la agricultura, mientras que el resto del año la vida se tornaba nómada y se basaba en la recolección y la caza. En el este del territorio los indios sobaipuris eran los más aguerridos a causa de la proximidad de los apaches, señalados como enemigos ancestrales en los mitos pimas. A pesar de ciertas diferencias entre estos grupos, todos ellos compartían patrones culturales y tenían el sentimiento de pertenencia a la nación pima u o'odham. Compartían la misma lengua, de la familia lingüística uto-azteca, con algunas variantes, como así señala el capitán Mange (Mange 1926: 259) o el padre Kino que aprendió la lengua para poder comunicarse con los tres grupos a lo largo de todas sus entradas.

Antes de la llegada de los pimas, los habitantes que ocupaban la Pimería eran los hohokam. A pesar de que el anhelo principal de Kino era el descubrimiento del paso por tierra para unir misiones pimas y californianas, el jesuita nunca perdió de vista su prioridad: la evangelización, por lo que también realizó entradas hacia el norte de Dolores, no sólo hacia el noroeste que era donde debía buscar el paso por tierra. Y 
así llegó a San Xavier del Bac en septiembre de 1692, a sesenta leguas al norte de Dolores. Se trataba de la ranchería más grande de la Pimería, que albergaba a unos ochocientos habitantes y de la que le habían dado noticia los indios de Dolores y otras misiones. Sus habitantes le hablaron de unas ruinas, que recibían el nombre de Casa Grande, unas leguas al norte, y Kino organizó una nueva entrada en noviembre de 1694, con una escolta militar en esta ocasión (Kino 1989: 29). Allí se encontraron ante un gran edificio de cuatro plantas, alrededor del cual se distribuían las ruinas de varias construcciones, restos de lo que debió de ser una gran ciudad. Disponía de una enorme acequia y en sus alrededores existían varias rancherías sobaipuris. En la época era como una especie de santuario para los pimas. Años más tarde, el padre Nentuig dibujaría un plano de una de estas edificaciones en su obra Descripción geográfica, natural y curiosa de la Provincia de Sonora (Nentuig 1792: 15v).

Según relataron los indios, Casa Grande había sido abandonada por sus habitantes, los hohokam, a causa de los ataques apaches y se habían dirigido hacia el sur y suroeste, hasta fundar la ciudad de México, siendo origen de la población mexicana (Mange 1926: 253; Kino 1989: 29). La cultura hohokam se desarrolló en estas zonas desérticas de la región desde el año 400 d.C. Existían semejanzas entre su organización social, su agricultura y los sistemas de riego y canales con los modelos empleados por los pimas. Los hohokam desarrollaron un importante comercio basado en adornos de conchas. Parece ser que esta cultura se desarrolló hasta aproximadamente el año 1450, aunque se desconoce la fecha exacta de la aparición de los pimas. Varios autores apoyan la teoría de que los pimas serían los descendientes de los hohokam, tras un grave descenso demográfico (Ruth Underhill en Eggan 1983: 736; Ezell 1983: 150), aunque también llegan a la conclusión de que los pimas pudieron instalarse en la región procedentes del oeste, inmediatamente después de la desaparición de los hohokam, adoptando entonces algunas características de sus antecesores en el territorio. En cualquier caso, la tradición pima sitúa su origen común en Casa Grande, establece la descendencia directa de los hohokam, habla de un rey llamado Montezuma y señala como causa de su desaparición los ataques apaches (Mange 1926: 252; Kino 1989: 29). También los ópatas - pueblo situado al norte de Sonora-compartían la creencia en Montezuma y la proveniencia del norte (Cañas 1977: 289). Las teorías actuales coinciden en la presencia de influencia mesoamericana en ciertos aspectos de la cultura pima.

No es posible establecer con certeza que la desaparición de los hohokam se debiera a los ataques apaches, aunque así lo establece la tradición pima. De hecho, en su mito del origen los apaches aparecen ya como sus enemigos ancestrales. Parece ser que los apaches llegaron a sus territorios históricos en torno a 1400 y los apaches orientales habrían llegado a la zona limítrofe con el este de la Pimería en torno a 1525. Por tanto, no serían los enemigos ancestrales que recoge el mito pima, pero sí unos recién llegados que estaban buscando establecerse en un territorio hacia el oeste, ocupado por los pimas, por lo que desde ese momento habrían empezado las hostilidades (Basso 1983: 463). Incluso es posible que los pimas hubieran quedado entre dos fuerzas de expansión en torno a esas fechas: los apaches hacia el oeste y los mohaves y quechán que intentaban desplazarse hacia el este (Jorgensen 1983: 699). 


\section{La metodología de Kino}

Kino supo ganarse a los pimas, afirmación que viene demostrada por diferentes hechos que el misionero recoge en su obra principal, Favores celestiales, y que pueden ser contrastados con otros escritos de militares de la época. Buscaba la autosuficiencia económica de las misiones que iba fundando y así, en cada pueblo que visitaba, dejaba cabezas de ganado y organizaba el trabajo agrícola, introduciendo nuevos cultivos como el trigo y frutales. La idea final era la creación de excedentes que poder enviar a California, para apoyar la subsistencia de sus nuevas misiones, en un entorno más hostil por las largas épocas de sequía. Porque finalmente Kino había conseguido despertar el interés del general Tirso González y se autorizó el envío de misioneros jesuitas de modo permanente. Y uno de estos jesuitas debía ser el padre Kino, al que acompañaría el padre Salvatierra. Sin embargo, las cosas volvieron a torcerse y, en esta ocasión, fueron las autoridades civiles las que no permitieron la salida de Kino de la Pimería. La causa fue que éste parecía ser el único capaz de mantener la paz en el territorio pima. Los indios le respetaban y escuchaban, de modo que su sola presencia parecía ser mucho más efectiva que un ejército. Así que finalmente fue el padre Piccolo quien acompañaría a Salvatierra a California. Pero esta nueva contrariedad no le desanimó. Al fin y al cabo, con su trabajo en tierras pimas conseguiría el mantenimiento de las misiones californianas y, además, todavía no había conseguido descubrir el paso por tierra. Kino ya estaba convencido de su peninsularidad y, a pesar de la creencia generalizada que le había conducido al error, sus conocimientos científicos le llevaron nuevamente al convencimiento de que California no era isla. Por tanto, tenía por delante una importante misión: continuar con la evangelización de la Pimería, al tiempo que seguía fundando misiones y recorriendo el territorio hacia el oeste como forma de crear un camino que uniera misiones pímicas y californianas, desafiando la aridez del territorio. Salvatierra y Piccolo se contagiaron del entusiasmo de Kino y le apoyaron en su proyecto.

Desde Dolores el jesuita mandaba mensajeros a diferentes pueblos anunciando su llegada. Hay que imaginar esas caravanas, anunciadas por la polvareda, al mando de Kino, formadas por caballos y ganado que nunca antes había sido visto por los habitantes de la Pimería. Kino aprendió la lengua pima y respetó las costumbres. Sabemos que era capaz de estar sentado durante horas, siguiendo la tradición pima, conversando y predicando, a la vez que sobre sus mapas mostraba a los pimas el océano y la tierra de donde procedía (Bolton 1984: 268). El jesuita recibía con agrado las danzas y celebraciones con que era recibido, a diferencia de otros misioneros. Podríamos decir que siempre tuvo presente el carisma ignaciano de ponerse en el lugar del otro. Evidentemente, al ser su principal misión la evangelización y la transmisión de la palabra de Dios, hubo ciertas costumbres y creencias que intentó erradicar, pero siempre a través del convencimiento y nunca de la imposición. Por otra parte hay que tener en cuenta que el hombre del hábito negro estaba de paso y traía productos beneficiosos para los pueblos pimas que, por consiguiente, eran aceptados de buen grado, en tanto no interferían con su modo de vida ni sus costumbres. Efectivamente, un problema al que Kino tuvo que enfrentarse siempre fue la escasez de misioneros en la Pimería. 


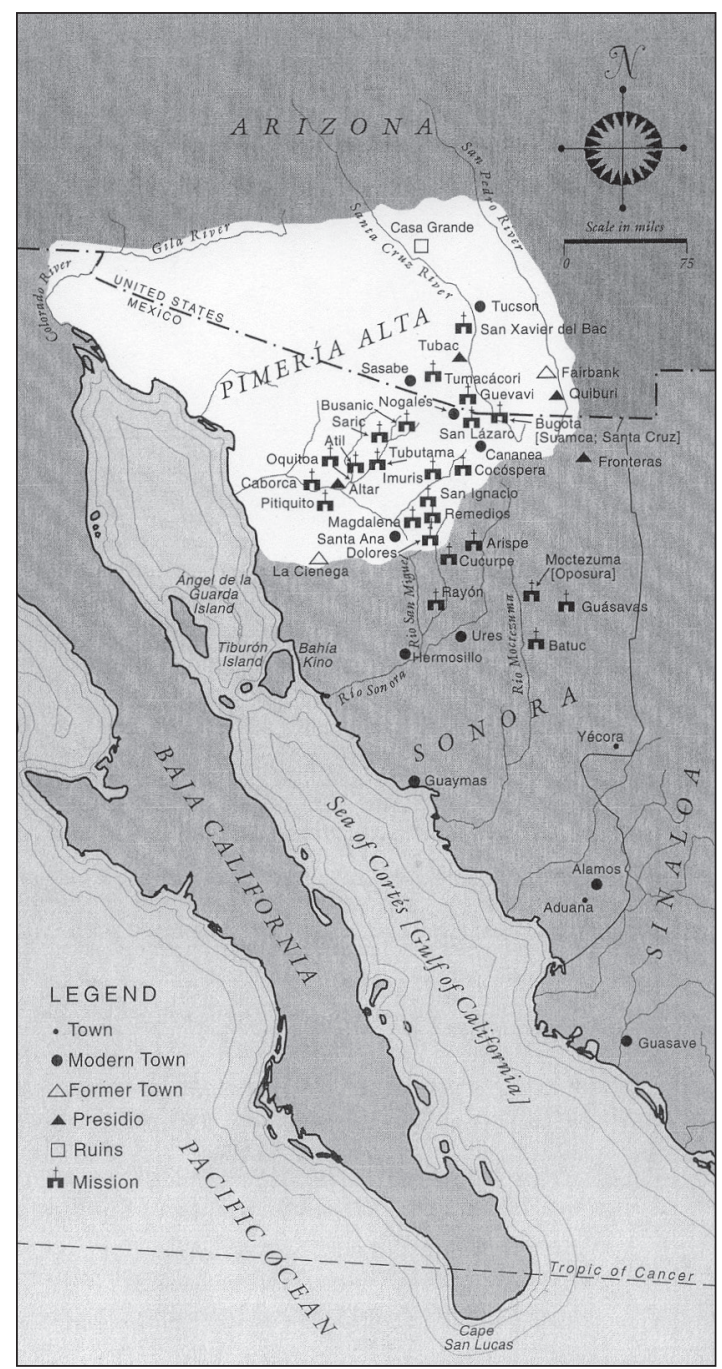

Figura 1: Mapa de Sonora y Arizona con las misiones del padre Kino (Olvera 1998: viii).

\section{Los compañeros de Kino}

El jesuita siempre estuvo rogando por la llegada de padres a la Pimería y no dudó en dirigirse al propio monarca a través de cartas. El general Tirso González apoyaba a Kino y sus planes. Su amistad personal se remontaba a los tiempos de su estancia en España en espera de la nave que debía conducirlos a tierras americanas. Sin embargo, muchos fueron los factores que retrasaron la llegada de misioneros: aparte de la peligrosidad de la travesía del océano, Kino tuvo que hacer frente a falsas acusaciones -contradicciones como las llama en sus escritos- a lo largo de su vida. Acusaciones 
que, por otra parte, constituyeron un factor común en la vida de la Compañía de Jesús en América. Se conservan numerosos testimonios de jesuitas desde Nueva España hasta el Paraguay lamentándose de las calumnias de que eran objeto.

El conflicto de intereses con los españoles del norte de Sonora fue evidente desde el principio. El jesuita se oponía claramente a cualquier tipo de abuso, lo que le ocasionó numerosos enemigos que buscaron en el descrédito el modo de que su empresa fracasara. Ante las acusaciones -abandono de sus misiones, maltratos, hostilidad de los indios- la Compañía enviaba un visitador y, aunque se terminaba demostrando la inocencia de Kino, en muchas ocasiones el mal ya estaba hecho y los misioneros que en un principio habían sido destinados a la Pimería, eran desviados a otros destinos supuestamente más seguros. Aun así, fueron llegando misioneros pero la mayoría permanecía poco tiempo.

Tres años después de la llegada de Kino a Dolores, sus peticiones fueron escuchadas y en 1690 llegaron cuatro padres a ocupar las misiones que ya estaban preparadas: Luis María Pinelli, Pedro de Sandoval, Antonio Arias y Juan del Castillejo. Ninguno permaneció más de tres años. En 1693 era el padre Agustín de Campos quien alcanzaba las misiones pimas, el único que llegó para quedarse. En 1695 llegaba Daniel Januske que abandonó tras la revuelta, un año después. El padre Gian Battista Barli murió en 1694, a los pocos meses de su llegada. Un año después murió Francisco Javier Saeta, a manos de los indios de la misión de Tubutama en la revuelta, la única que se produjo en la época de Kino, y que éste relató con detalle en una de sus obras (Kino1961). También murieron dos de los tres padres que llegaron en 1701, Ignacio de Iturmendi y Francisco Gonzalvo, a causa de la enfermedad, y el tercero, Juan de San Martín, fue trasladado a Sonora por motivos de salud. El resultado es que en 1702 vuelven a quedar solos Kino y Campos, siempre acompañados por la presencia y apoyo del capitán Mange. Todavía vería Kino a dos jesuitas más, Jerónimo Minutuli y Domingo Crescoli, pero ninguno permanecía en la Pimería a la muerte del pionero en 1711.

La situación es que entre 1687 y 1711, dieciocho jesuitas alcanzaron las misiones pimas pero, excepto Kino y Campos, no consiguieron perseverar. La vida en la frontera era extremadamente dura y los misioneros debían enfrentarse a dos enemigos poderosos: la soledad y las enfermedades. A la vista de estos datos es posible concluir que Kino sí recibió el apoyo de sus superiores religiosos y que la evangelización de la Pimería sí entró en los planes de evangelización de la Compañía de Jesús, pero las dificultades propias del territorio fueron causa de que siempre faltaran misioneros en la Pimería.

\section{Los pimas en la época de Kino}

¿Cómo eran los pimas que encontró el padre Kino? A partir de los datos proporcionados por él y sus compañeros es posible obtener la siguiente información acerca de la vida y costumbres de los pimas. Son muchos más los datos que conocemos que 
han permitido elaborar una completa etnografía ${ }^{2}$ a partir de otros relatos posteriores a Kino -y que corroboran sus informaciones-, pero el objeto de este punto es ver qué podemos saber de los pimas simplemente con los primeros relatos que se escribieron sobre ellos, ciñéndonos exclusivamente a la época de Kino, es decir, a los primerísimos contactos. Se trata de conocer a los habitantes de la Pimería a través de los ojos de Kino, el capitán Mange y el teniente Martín Bernal.

La principal fuente de información sobre los pimas son claramente los escritos del padre Kino, aunque hay que señalar que no aportó demasiados datos sobre su cultura, ya que sus intereses eran otros, especialmente la evangelización y las exploraciones, además de combatir las acusaciones que le atacaban a él y a los pimas. En cualquier caso, se pueden obtener datos importantes a partir, sobre todo, de dos de sus obras: Favores celestiales y la biografía del padre Saeta. Asimismo otros testigos de la época plasmaron sus impresiones sobre la Pimería y sus habitantes: Mange y Martín Bernal.

El capitán Juan Mateo Mange es autor del Diario de las exploraciones en Sonora (Mange 1926), obra escrita en 1721 que relataba siete de las aproximadamente nueve entradas que realizó junto a Kino. Aporta más datos etnográficos que éste, proporciona detalles pormenorizados de la metodología de las entradas y es prueba de la veracidad de los datos señalados por Kino. Mange llegó a México en 1692 desde su Aragón natal. Era sobrino del gobernador militar de Sonora, Domingo Jironza Petriz de Cruzat. Un año después de su llegada fue nombrado teniente de alcalde mayor de Sonora y se convirtió en compañero inseparable del padre Kino en muchas de sus entradas a la Pimería. En la América española los papeles del misionero y del militar podían llegar a intercambiarse, de modo que el capitán colaboró en ocasiones en las tareas de evangelización de su compañero de viaje. A pesar de que unos años más tarde Mange protagonizó un conflicto con la Compañía de Jesús ${ }^{3}$, su amistad y lealtad hacia Kino fue tal que incluso llegó a arriesgar su vida por él durante el levantamiento de 1695. Cuando un grupo de pimas se dirigía hacia la misión de Dolores, con intenciones claramente hostiles después de dar muerte al padre Saeta, Mange intentó convencer a Kino de la conveniencia de huir. Ante la negativa a abandonar su misión, el capitán decidió permanecer y recibió la confesión, convencido de su próxima muerte (Mange 1926: 243). Finalmente, el ataque no llegó a producirse.

El teniente Cristóbal Martín Bernal acompañó a Kino y Mange en la expedición de noviembre de 1697 al río Gila y Casa Grande. Su diario recoge datos sobre los tamaños de las rancherías, las distancias entre unas y otras, el número de habitantes y algunas de sus costumbres y aporta información sobre la metodología misionera. $\mathrm{Su}$ testimonio adquiere importancia porque confirma los relatos de sus compañeros (Martín Bernal 1792: 292r-307r; Kessell et al.1966: 35-47).

La veracidad de los datos recogidos por los tres autores es clara puesto que ellos mismos se preocuparon de aportar pruebas que así lo demostraran. Dice Martín Bernal: «(...) y para que conste por diligencia de que doy fe, y lo firmé con los testigos»

\footnotetext{
2 Para una etnografía original y completa acerca de los pimas: Navajas 2009 y 2011.

3 En un documento de 1706, Mange alabó la labor de Kino y Campos, pero surgió el conflicto de intereses habitual y optó por tomar partido por mineros y hacendados sugiriendo que la fase misionera debería darse por terminada, secularizando las misiones. Sin embargo, en un escrito posterior, en 1720, volvió a referirse favorablemente a los jesuitas (Spicer 1962: 128; Bolton 1984: 557-565).
} 
(Polici 1792: 302v). Los testigos que en esta ocasión dejaron constancia con su firma fueron el propio Kino, el alférez Francisco de Acuña y tres soldados. Mange dio fe en una carta fechada en 15 de mayo de 1702 de que era cierto todo lo que relataba el padre Kino sobre las entradas, recursos naturales de la Pimería y bondad de los indios. Esta carta quedó recogida en el diario del jesuita bajo el título «Certificación del señor alcalde mayor desta provincia, Juan Mateo Mange, acerca de la carta e informe de cuatro pliegos al padre visitador Antonio Leal, y acerca de la entrada al paso por tierra a la California» (Kino 1958:173). En varias de sus cartas, Kino pedía a los soldados que le acompañaban que firmaran para certificar la verdad de su contenido, tal y como era costumbre en la época. La Compañía de Jesús enviaba visitadores a los distintos territorios de misiones para confirmar su buen funcionamiento y también cuando surgían acusaciones. Kino las sufrió frecuentemente, ya que se convirtió en el gran defensor de los pimas frente a los intentos de abuso por parte de mineros y hacendados de Sonora que buscaban mano de obra barata. Esto le valió su enemistad y fue el origen de una constante serie de rumores y acusaciones, como ya hemos señalado. La Compañía era la primera interesada en aclarar estas situaciones cuando surgían, por lo que Kino recibió la visita de sus superiores en varias ocasiones, visitas que finalizaban con el veredicto de inocencia, pero que supusieron el retraso de la llegada de más padres.

No se sabe con certeza si existieron contactos con los pimas anteriores a Kino. Es posible que Cabeza de Vaca y sus compañeros, en su largo recorrido desde Florida, llegaran hasta el río Gila. En cualquier caso, si llegó a ser así, no existen documentos que proporcionen datos sobre los habitantes de la Pimería. Francisco Vázquez de Coronado y fray Marcos de Niza recorrieron el sureste de la actual Arizona entre 1538 y 1540, pero no se puede asegurar que los pimas ya estuvieran instalados entonces en el territorio. Al no hallar oro ni las míticas ciudades de Cíbola, la zona perdió su interés y permaneció como tierra incógnita hasta la llegada del padre Kino (Eckhart 1960: 165; Bannon 2001: 15-16). Por tanto, las primeras noticias escritas sobre los pimas las proporciona el jesuita.

El nombre de pima se lo dieron los españoles, al ser los habitantes de la Pimería, ya que ellos se llamaban a sí mismos con el nombre de otama y en plural ohotoma (Russell 1908: 19). El padre Velarde, el sucesor de Kino en Dolores a su muerte, escribe también para referirse a los pimas otama en singular y ootoma en plural (Mange 1926: 298). Cuando querían diferenciarse de los pápagos u otros pueblos se hacían llamar «Gente del río». Según explica el jesuita Velarde, los españoles dieron este nombre a los indios porque repetían mucho la palabra pim que quiere decir «no» (Mange 1926: 298; Bolton 1984: 246).

Cuando Kino llegó al pueblo de Cosari en 1687 lo bautizó con el nombre de Nuestra Señora de los Dolores, convirtiéndose en su hogar hasta su muerte en 1711. Comenzó inmediatamente sus primeras expediciones por el territorio y encontró grupos que vivían de manera sedentaria en rancherías a lo largo de los ríos Magdalena, Santa Cruz, Altar y San Miguel. Estos pueblos no seguían una pauta en cuanto al número de habitantes. El teniente Martín Bernal recogió datos acerca de tamaños y distancias en su recorrido por el río Gila en noviembre de 1697: la ranchería de Quiburi contaba con 97 casas y 486 habitantes y otras siguiendo el curso del río, de las que no 
da el nombre, tenían por ejemplo 23 casas, unas grandes y otras pequeñas, con 140 habitantes, o 20 casas con 123 habitantes; otra tenía 12 casas con 60 habitantes y una ranchería llamada Ojío contaba con 73 casas y 315 habitantes. Tanto el jesuita como el oficial coincidían al afirmar que el Bac era con mucho la ranchería más grande de la Pimería. Según Martín Bernal tenía 176 casas que albergaban a 830 habitantes. Las distancias que señala entre las rancherías varían desde la media legua ${ }^{4}$ hasta las doce leguas (Martín Bernal 1792: 294r-302v; Kessell et al. 1966: 35-47).

También Mange dio detalles de tamaños y distancias. En su primer viaje con Kino, en 1693, pasaron por Magdalena, a 12 leguas de Dolores, con 120 habitantes; tras 4 leguas llegaron al Tupo con 200 habitantes y a 8 leguas al noroeste alcanzaron la ranchería del Bosna con 100 habitantes (Mange 1926: 215). En la entrada realizada en noviembre de 1697 pasaron por la ranchería de Santa Cruz con 25 casas y 100 habitantes y a una legua al norte llegaron a Quiburi, la ranchería del capitán Coro, con 100 casas y 500 habitantes (Mange 1926: 248), dato que coincide aproximadamente con las cifras proporcionadas por Martín Bernal. Efectivamente, las distancias son variables pero nunca parecen superar las 12 leguas, y los tamaños de las rancherías no siguen una pauta determinada. Los grupos más próximos al mar de California eran más reducidos, de unas 30 personas (Mange 1926: 263).

Los pimas desarrollaron un sistema de riego para aprovechar el agua de los ríos, probablemente heredado de los hohokam, aunque a diferencia de éstos no utilizaron el adobe para la construcción. De hecho, los pimas no construyeron con este material hasta la llegada de Kino que lo utilizó para las iglesias y las viviendas de los misioneros. El agua era un bien preciado y su aplicación prioritaria iba claramente dirigida a su subsistencia, al cultivo del maíz principalmente.

Sin embargo, los patrones de asentamiento que Kino encontró en las entradas que realizó hacia el mar de California eran diferentes. En esta zona no había ríos, por lo que los pápagos desarrollaban una vida seminómada. Cuando la estación lo permitía se asentaban y basaban su economía y su dieta en la agricultura. Pero cuando el clima así lo exigía, debían desplazarse y dedicarse a la recolección y a la caza, abandonando temporalmente la agricultura.

No existía un trabajo colectivo organizado, pero varios pueblos se unían para construir diques y canales que todos usarían. Tampoco existía una persona encargada de supervisar el mantenimiento de los canales, pero se supone que por el uso colectivo y el bien de la comunidad todos participaban en su mantenimiento. Los pimas fueron capaces de aunar sus esfuerzos en beneficio del grupo sin necesidad de desarrollar un poder centralizado ni una autoridad religiosa, y sin necesidad de establecer terrenos exclusivos para el poder político ni un trabajo obligatorio para éste. Aunque existía la diferenciación en el trabajo por sexos, tanto hombres como mujeres participaban en las labores agrícolas. Por tanto, se organizarían a través de su sistema de parentesco, a diferencia de los pueblo, por ejemplo, donde este tipo de tareas eran obligatorias una vez al año (Jorgensen 1983: 698). De ahí que fueran reacios a aceptar que el misionero les obligara a trabajar unos días determinados a la semana para las tierras de la misión, puesto que no entraba en sus esquemas de organización. Tanto Kino

4 Una legua equivalía aproximadamente a 4 kilómetros (Robles 1939: 11; Burrus 1963: 12). 
como todos los misioneros que trabajaron en la Pimería se lamentan de la necesidad de tener que repetir una y otra vez las órdenes referidas a las pautas que deseaban introducir para sistematizar el trabajo colectivo -en las tierras y en la construcción de la iglesia-, al no comprender que la desobediencia se debía a la falta de interés por un factor ajeno a su tradición.

Las construcciones, separadas unas de otras dejando espacios abiertos, se elaboraban con ramas, hojas y esteras de hierbas que se colocaban en forma de bóveda sobre unos palos. Cada familia ocupaba una construcción sin ventanas que utilizaba para dormir y guardar sus pertenencias: esteras, calabazas para almacenar agua, alguna olla para tostar maíz, arcos, flechas, algún carcaj y porras. Además en cada ranchería había varios tipos de construcciones comunitarias como las ramadas, que proporcionaban sombra y servían como lugar de reunión. Otras construcciones se utilizaban para almacenar alimentos y como lugar de aislamiento de las mujeres durante la menstruación (Mange 1926: 313).

Los hombres pimas se cubrían con mantas de algodón de colores, mientras que las mujeres llevaban unas faldas de gamuza o de corteza de sauce e iban desnudas de cintura hacia arriba, excepto en invierno cuando se cubrían con pieles de conejo o mantas de algodón. Los hombres pápagos iban desnudos (Mange 1926: 216, 312). Kino no habla del vestuario pero probablemente trataría de cubrir sus cuerpos. Se conservan cartas en las que solicita a sus superiores calzado y tela en abundancia para destinar a vestuario (Kino 1987: 31-33). Probablemente, el hecho de encontrar a los pimas desnudos o semidesnudos no debió de llamarle la atención después de su estancia en California, por lo que no lo consideraría como algo digno de ser reseñado.

Aunque ni Kino ni Mange hacen referencia a los tatuajes, por relatos posteriores de jesuitas que misionaron en la Pimería, sabemos que se adornaban el cuerpo y que no se trataba de un simple adorno, sino que el proceso iba acompañado de un ritual y era considerado como un elemento diferenciador frente a otras naciones. Por medio de estos tatuajes el pueblo reconocía a sus habitantes y existía la creencia de que quien no estuviera tatuado no lograría nunca llegar hasta Montezuma (Nentuig c. 1764: 297v; Segesser 1945: 145; Och 1965: 124-125). A lo que sí se refiere Mange es a la pintura corporal. Los pimas se pintaban el rostro, aunque no especifica en qué ocasiones (Mange 1926: 264). Según relatos posteriores, sólo se aplicaría con motivo de determinadas celebraciones o en caso de guerra. Se empleaban los colores rojo, verde, amarillo, azul y blanco que se obtenían mezclando tierra con otros elementos. La pintura se almacenaba en forma de bolas que se disolvían en agua para su aplicación. Se extendía con los dedos por el rostro y desde el cuello hasta la cintura en líneas de diferentes colores o en zigzag (Och 1965: 126). Por lo llamativo de la decoración corporal, llama la atención que ni Mange ni Kino dediquen unas líneas, ya que estuvieron presentes en muchos enfrentamientos por lo que con toda seguridad tuvieron la ocasión de presenciar estos preparativos.

La cerámica era poco elaborada pero la cestería, labor exclusiva de las mujeres, alcanzó una gran perfección y así aparece alabada en varios escritos. La cestería se producía no sólo para uso propio, sino también para el intercambio comercial, junto con mantas de algodón y alimentos, aunque en época de Kino el comercio práctica- 
mente había desaparecido a causa de los ataques apaches entre el territorio hopi y pima (Mange 1926: 312).

Los pimas se alimentaban, entre otros productos, de liebres, venados y conejos, al menos en ocasiones festivas, así como de pitahaya y maíz. Los indios del Gila eran pescadores, utilizaban redes y otros instrumentos de pesca, y se alimentaban de pescado, maíz, frijol y calabazas (Kino 1958: 122-124). Existían dos cosechas anuales de maíz, la base de la dieta. Además consumían pinole y judías de mezquite. En el valle de San Pedro se cultivaba maíz, frijoles, calabazas y algodón, que tejían en mantas que teñían de varios colores (Mange 1926: 250). El capitán describe los alimentos con que son obsequiados en sus entradas por la Pimería: frijoles cocidos y harina de maíz y en otra ocasión les ofrecieron «jícaras grandes de calabaza cocida, frijol y pinole» (Mange 1926: 249-250). Los pimas cazaban venados y organizaban grupos de caza entre diferentes rancherías cuando era la época, ya que Mange en su primer viaje por la Pimería en 1693 explica que al llegar a la ranchería del Pitquín había poca población porque la mayoría estaba cazando ciervos, y lo mismo sucedió al llegar a Caborca (Mange 1926: 217). El militar pasa por campos fértiles que producían maíz, frijol y calabaza, mientras que al irse acercando al mar de California, las tierras se convertían en estériles y los indios se alimentaban de raíces, langostas, mariscos (Mange 1926: 219), ciervos y carneros salvajes (Mange 1926: 284), camotes silvestres, pitahaya y «una frutilla colorada» (Mange 1926: 216). El alcohol se solía consumir en ocasiones rituales o en celebraciones festivas, pero no de manera cotidiana. En este contexto la embriaguez era admitida socialmente. Se obtenía a partir de plantas que normalmente se consumían como alimento, como la pitahaya ${ }^{5}$, pero eran sometidas a un proceso de fermentación que las convertía en alcohólicas.

No existe mucha información sobre la organización social antes de la llegada de los españoles a la Pimería y los relatos de los jesuitas y militares apenas proporcionan datos. La única referencia que hace Mange en su diario es en ocasión del segundo viaje que realizó con Kino por la Pimería, en 1694, y al llegar a las rancherías de Santa Teresa y Atí, a tres leguas de la misión del Tubutama, dice que en ellas vivían «parcialidades de familias emparentadas» (Mange 1926: 224). El matrimonio apenas implicaba rituales, bastaba con que la pareja comenzara a convivir. Del mismo modo la separación se hacía efectiva con el abandono de una de las partes de la vivienda común (Mange 1926: 315). Se trataba de una sociedad patrilineal, basada en la familia extensa formada por una pareja, sus hijos casados e hijas no casadas, en la que estaba permitida la poliginia.

Los pimas carecían de una organización política centralizada. Cada pueblo tenía su propio jefe y sólo se unían en ocasiones muy concretas como ante ataques apaches o en partidas de caza. Surgía entonces la figura de un jefe común, cuya función cesaba al terminar la actividad. El puesto de jefe no era hereditario y cualquier hombre podía acceder a ejercer la jefatura, a través del convencimiento a los suyos de que era el más apropiado. Existía, sin embargo, un claro sentimiento de pertenencia a la nación pima. Kino, Mange y Martín Bernal hacen referencia en diversas ocasiones a lo largo

\footnotetext{
5 Planta de la familia de las cactáceas que comprende varios géneros. La que proporciona frutos comestibles es el cereus thurberi.
} 
de sus escritos a algunos de estos jefes: Cola de Pato -jefe de Cocóspera- o Coro -jefe de la ranchería sobaipuri de Quiburi- con los que llegaron a entablar amistad (Mange 1926: 314; Kino 1958: 181-182).

La guerra constituía un factor central en la cultura pima. Gran parte de su cultura giraba en torno a la defensa de los ataques apaches, hecho que condicionaba varios aspectos de su vida cotidiana: las rancherías no estaban demasiado alejadas unas de otras para facilitar la defensa, su mito de la creación ya hace referencia a la enemistad entre ambos grupos, los apaches son señalados como causantes del abandono de Casa Grande y lleva al desarrollo de rituales de purificación preparatorios a la guerra y posteriores, acompañados de danzas de la victoria. Al regresar victoriosos de una campaña, se celebraban danzas en rueda, acompañadas por cantos y gritos, alrededor del fuego y de un palo del que colgaba una cabellera o algún miembro del enemigo muerto (Mange 1926: 313). Kino y Mange, en una entrada realizada en noviembre de 1697, hicieron noche en Quiburi, la ranchería del capitán Coro, donde fueron recibidos con un «exquisito baile en forma circular, en cuyo centro una alta asta donde pendían 13 cabelleras, arcos, flechas y otros despojos de otros tantos enemigos apaches que habían muerto». Lejos de espantarse ante tal costumbre, los soldados españoles se unieron a las danzas (Mange 1926: 248; Kino 1958: 121). Las armas empleadas eran arcos, macanas y flechas, a las que aplicaban un veneno tremendamente efectivo (Mange 1926: 239).

La defensa frente a los apaches fue causa de que los pimas se aferraran a sus tradiciones como modo de preservar su identidad, de modo que debieron concentrar sus esfuerzos en tácticas de defensa. Su prioridad cotidiana era sobrevivir a los ataques apaches, los mismos que habían llevado a la desaparición de sus antecesores, los habitantes de Casa Grande. Con la llegada de los españoles a su territorio, los pimas actuaron como barrera de defensa para las poblaciones españolas de Sonora.

Pero no todo en la vida de un pima era la guerra contra apaches, janos y jocomes. También dedicaban parte de su tiempo al entretenimiento y así practicaban juegos de pelota. El guaquimari consistía en golpear con el pie una pelota de madera. Dos equipos competían para cubrir un recorrido de un par de horas en el menor tiempo posible (Mange 1926: 264-265, 313). Otro juego es el llamado patole que consistía en hacer botar sobre una piedra cuatro cañas o palos con unas líneas talladas, de modo que caían al suelo señalando un número determinado por estas marcas. El primero que llegaba al número establecido era el vencedor (Mange 1926: 313). Este juego se seguía practicando a principios del siglo XX (Russell 1908: 175). Los pimas amaban la música y la danza. Kino agradece los bailes que se celebraban en su honor con ocasión de sus visitas, bailes y cantos que podían prolongarse toda la noche. Otros misioneros posteriores, sin embargo, no supieron entender esta costumbre e intentaron erradicarla sin éxito.

Respecto al mundo de las creencias, la tradición pima recoge el mito universal del diluvio (Kino 1958: 253) y hace referencia a un tal Jitoy y dos familias que habían sobrevivido al diluvio. Existía la creencia de que en la luna había un muchacho que había sido llevado hasta allí por una grulla. De esta manera explicaban las manchas de la luna, aunque otros afirmaban que se trataba de un coyote y no de un muchacho. Los hombres eran sepultados con sus arcos, flechas y calabazas con agua, lo que 
podría demostrar una creencia en otra vida, aunque no distinguían entre premio y castigo (Mange 1926: 314-316). Sin embargo, no se observa la presencia de ídolos ni manifestaciones externas claras acordes a la concepción de la espiritualidad de los misioneros. La interacción de los pimas con las fuerzas de la naturaleza que les rodeaban con sus poderes estaba presente en la vida diaria, tratando de armonizar la convivencia.

Kino no habla de chamanes pero sabemos que existían por relatos posteriores (Velarde 1977: 60-61; Nentuig 1980: 58; Pfefferkorn 1989: 227). Se trataba de hombres que tenían la capacidad de atraer la lluvia, diagnosticar y curar enfermedades y ver el futuro. En general, los misioneros no hablaron demasiado de los chamanes, puesto que prefirieron no ahondar en ciertas situaciones para las que no encontraban explicaciones lógicas y además en muchos casos se convirtieron en su mayor obstáculo para que su evangelización llegara al pueblo.

Kino destaca el trato afable que normalmente recibió por parte de los pimas a lo largo de sus múltiples expediciones por el territorio. Llevó a la práctica la aplicación de sacramentos como el bautismo y el matrimonio, aunque las entradas en los libros de las misiones donde debían quedar reflejados no son numerosas. Era norma no aplicar los sacramentos alegremente, sin una preparación previa y, al no haber nunca muchos misioneros en la Pimería, parece que el sistema de creencias tradicional no sufrió muchas alteraciones y la práctica de la nueva religión quedaría en general limitada a aspectos externos, aunque habría también conversiones. El hombre del hábito negro pasaba, predicaba, se sentaba a conversar con los pimas, pero no permanecía, por lo que no fue nunca considerado como un elemento que pusiera en peligro su identidad. Kino fue una de esas personas que supo ponerse en el lugar del otro -tal y como había predicado San Ignacio- de modo que enseñaba pero no obligaba. Su carácter comprensivo y su carisma personal le abrieron las puertas de la Pimería y, excepto el levantamiento de 1695, su relación fue siempre pacífica. Por eso, cuando ya tenía todo a punto para ser trasladado a su ansiado destino, las misiones californianas, las autoridades civiles impidieron su marcha. La presencia del jesuita constituía una garantía de paz en un territorio hostil.

\section{Conclusiones}

El padre Kino murió el 15 de marzo de 1711 en la misión de Magdalena. Se encontraba allí en compañía del padre Campos, con ocasión de la dedicación de un altar a San Francisco Javier. En el año 2011 se ha cumplido, pues, el tercer centenario de su fallecimiento. Tras su muerte, las misiones del norte de la Pimería quedarían abandonadas por falta de misioneros hasta que en 1732 llegaron los padres Grazhoffer, Segesser y Keller escoltados por el capitán Anza, reclamados directamente al rey por el obispo de Durango. Así cobró un nuevo impulso la actividad misionera en esta zona, hasta la expulsión de la Compañía de Jesús decretada por el rey Carlos III en 1767. Se conservan de esta época varias relaciones de los jesuitas que aportan gran cantidad de datos que permiten completar una etnografía pima. Además, se llevaron a cabo diversas expediciones militares con el objetivo de inspeccionar los presidios 
de la frontera septentrional, ante el aumento de la inseguridad. El resultado son varios informes de gran interés histórico como el elaborado por el brigadier Pedro de Rivera de 1727 (Rivera Villalón 1727 y 1792), el del licenciado Rodríguez Gallardo de 1750 (Rodríguez Gallardo 1792) y del ingeniero Lafora que participó en la expedición del marqués de Rubí entre 1766 y 1768 (Lafora $c$. 1768).

A principios del siglo XX coincidieron dos hechos importantes que llevaron a la revitalización de los estudios de la historia de la frontera norte. Por un lado, fue publicada la primera etnografía completa sobre los pimas, que pone de manifiesto que gran parte de las costumbres recogidas por Kino y Mange se seguían conservado doscientos años después (Russell 1908). Y a raíz del descubrimiento del manuscrito de Kino por el profesor Bolton en 1907 en el Archivo General y Público de México, la figura del jesuita se convirtió en objeto de estudio. Con ocasión del tercer centenario de su fallecimiento han surgido diferentes publicaciones que son prueba de que las investigaciones sobre Kino, los pimas y la frontera norte siguen despertando interés y constituyen un tema de actualidad. De hecho, el Capitolio de Washington alberga desde 1965 una estatua del padre Kino como representante del estado de Arizona en la que se puede leer: «Explorador, historiador, ranchero, fundador de misiones y apóstol de los indios».

\section{Referencias documentales}

LAFORA, Nicolás de

c. 1768 «Informes sobre las Provincias Internas por el Ingeniero Lafosa (sic)». Madrid: Museo Naval. Ms. 567, Virreinato de Méjico, tomo I, doc. 9, ff. 205r-241r.

Martín Bernal, Cristóbal (ver Polici, Horacio)

1792 Relación. Madrid: Real Academia de la Historia. Colección de Memorias de Nueva España. Materiales para la Historia de Sonora, tomo XVI, ff. 294r-302v.

Nentuig, Juan de

c. 1764 «Extracto de Noticias de Sonora sacado de Manuscritos del Docto Cav. D. Eug ${ }^{\circ}$ Sta. Eliza que intitula Descripción de Californias». Madrid: Museo Naval. Ms. 567, Virreinato de Méjico, tomo I, doc. 13, ff. 287-300v. (Es copia de los capítulos III, IV y V de la Descripción de Nentuig).

1792 «Descripción geográfica, natural y curiosa de la Provincia de Sonora por un amigo de el servicio de Dios y de el Rey Nuestro Señor. Año de 1764». Madrid: Real Academia de la Historia. Colección de Memorias de Nueva España. Materiales para la Historia de Sonora, tomo XVI, ff. 1r-103r.

Polici, Horacio

1792 «Relación del estado de la Pimería que remite el padre visitador Horacio Polici por el año de 1697». Madrid: Real Academia de la Historia. Colección de Memorias de Nueva España. Materiales para la Historia de Sonora, tomo XVI, ff. 292r307r. (Incluye la relación del teniente Martín Bernal).

Rivera Villalón, Brigadier Pedro de

1727 «Descripción de las provincias internas de la Nueva España hecha de orden del Excmo. Señor Virrey de aquel reyno por D. Francisco Albarez Barreiro, teniente Coronel de Ynfantería é Ingeniero en Gefe de la Provincia de Tejas en conformi- 
dad del capítulo 21 de las instrucciones que por el mismo Sr. Virrey se le dieron al Brigadier D. Pedro de Rivera Villalón». Madrid: Biblioteca del Palacio Real. Miscelánea de Ayala, tomo XII, ff. 163v-173r.

1792 «Informe del Sr. Brigadier, Visitador General, al sr. Virrey, del estado de las misiones de la Compañía en las provincias de Sinaloa, y Sonora». Madrid: Real Academia de la Historia. Colección de Memorias de Nueva España. Materiales para la Historia de Sonora, tomo XVI, ff. 334v-339r. (Original de 1727).

Rodríguez Gallardo, José Rafael

1792 «Señor Teniente Coronel Don Diego Ortiz y Parrilla, Governador, y Capitán General interino de estas provincias». Madrid: Real Academia de la Historia. Colección de Memorias de Nueva España. Materiales para la Historia de Sonora, tomo XVI, ff. 408v-454v. (Original de 1750).

\section{Referencias bibliográficas}

BANNON, John F.

2001 The Spanish Borderlands Frontier, 1513-1821. Albuquerque: University of New Mexico Press.

BAsso, Keith H.

1983 «Western Apache», en Handbook of North American Indians, 10: Southwest, Alfonso Ortiz, ed., pp. 462-488. Washington: Smithsonian Institution.

Bolton, Herbert E.

1984 Rim of Christendom. A Biography of Eusebio Francisco Kino, Pacific Coast Pioneer [1936]. Tucson: The University of Arizona Press.

Burrus, Ernest J. (ed.)

1963 Misiones norteñas mexicanas de la Compañia de Jesús (1751-1757), Biblioteca Histórica Mexicana de Obras Inéditas, 25. México: Antigua Librería Robredo de José Porrúa e Hijos, Sucs.

CAÑAs, Cristóbal de

1977 «Estado de la provincia de Sonora, con el catálogo de sus pueblos, iglesias, padres misioneros, número de almas capaces de administración, lenguas diversas que en ella se hablan y leguas en que se dilata; con una breve descripción de la Sonora jesuítica según se halla por el mes de julio de este año de 1730. Escrito por un padre misionero de la provincia de la Compañía de Jesús de Nueva España», en Etnología y misión en la Pimería Alta, 1715-1740, de Luis González R., pp. 279-304. México: Instituto de Investigaciones Históricas, Universidad Nacional Autónoma de México. (No se ha encontrado el documento original. Una copia manuscrita se halla en el Archivo General de la Nación en México, volumen 16 de Historia, ff. 139-160v).

ECKHART, George B.

1960 «A Guide to the History of the Missions of Sonora, 1614-1826». Arizona and the West. A Quarterly Journal of History 2 (2): 165-182. Tucson.

EGGAN, Fred

1983 «Comparative Social Organization», en Handbook of North American Indians, 10: Southwest, Alfonso Ortiz, ed., pp. 723-742. Washington: Smithsonian Institution. 
Ezell, Paul H.

1983 «History of the Pima», en Handbook of North American Indians, 10: Southwest, Alfonso Ortiz, ed., pp. 149-160. Washington: Smithsonian Institution.

JORGENSEN, Joseph G.

1983 «Comparative Traditional Economics and Ecological Adaptations», en Handbook of North American Indians, 10: Southwest, Alfonso Ortiz, ed., pp. 684-710. Washington: Smithsonian Institution.

Kessell, John L., Jackson F. Smith y Francis J. Fox

1966 Father Kino in Arizona. Fénix: Arizona Historical Foundation.

KinO, Eusebio Francisco

1958 «Flores (sic) celestiales de Jesús y de María Santísima y del gloriosíssimo apóstol de las Indias, Francisco Xavier», en Viajes por Norteamérica, Manuel Ballesteros Gaibrois, director; Mario Hernández Sánchez-Barba, notas, pp. 89-225. Col. de Textos Anotados, Biblioteca Indiana II. Madrid: Aguilar. (El documento original se conserva en el Archivo General y Público en México, Sección de Misiones, tomo 27).

1961 Vida del P. Francisco J. Saeta, S.J. Sangre misionera en Sonora, Ernest J. Burrus, prólogo y notas. Col. Figuras y Episodios de la Historia de México, nº 102. México: Jus. (El documento original se conserva en la Biblioteca Nacional de México, Colección General, Ms. 1118, ff. 139r-198r).

1987 «Memoria del Partido de $\mathrm{N}^{\mathrm{a}} \mathrm{S}^{\mathrm{a}}$ de los Dolores para el año 1707», en Cartas a la Procura de Misiones, Manuel Pérez Alonso, introducción y notas, pp. 31-33. México: Universidad Iberoamericana. (La carta original se conserva en el Archivo Histórico de la Provincia de México, Ms. 1218).

1989 Las misiones de Sonora y Arizona (comprendiendo: la crónica titulada «Favores celestiales» y la «Relación diaria de la entrada al Noroeste»), Francisco Fernández del Castillo, versión paleográfica e índice; Emilio Bose, prólogo. México: Porrúa.

Mange, Juan Mateo

1926 Luz de Tierra Incógnita en la América Septentrional y Diario de las Exploraciones en Sonora, versión, notas e índice alfabético por Francisco Fernández del Castillo. Publicaciones del Archivo General de la Nación, tomo X. México: Talleres Gráficos de la Nación, «Diario Oficial». (El documento original se conserva en el Archivo General de la Nación en México, volumen 393, Historia, ff. 47r-95v).

Navajas Josa, Belén

2009 El padre Kino y la Pimería: aculturación y expansión en la frontera norte de Nueva España. Tesis doctoral. Madrid: Universidad Complutense de Madrid.

2011 Aculturación y rebeliones en las fronteras americanas. Las misiones jesuitas en la Pimería y el Paraguay. Cuadernos Americanos Francisco de Vitoria, 13. Madrid: Universidad Francisco de Vitoria.

Nentuig, Juan de

1980 Rudo ensayo. A description of Sonora and Arizona in 1764, Alberto Francisco Pradeau y Robert R. Rasmussen, traducción y notas. Tucson: University of Arizona Press.

Och, José

1965 Missionary in Sonora. The Travel Reports of Joseph Och, S.J. 1755-1767, Theodore E. Treutlein, traducción y notas. San Francisco: California Historical Society. (Documento original en la Bancroft Library). 
Olvera, Jorge H.

1998 Finding Father Kino. The Discovery of the remains of Father Eusebio Francisco Kino, S.J. 1965-1966. Tucson: Southwestern Mission Research Center.

PfefFerkorn, Ignaz

1989 Sonora: A Description of the Province, Theodore Treutlein, trad. y notas; Bernard L. Fontana, prólogo. Tucson: University of Arizona Press. (Documento original en alemán, traducido por T. Treutlein en 1940 a partir de la primera edición publicada [Köln am Rheine 1794-1795] con el título Beschreibung der Landschaft Sonora samt andern merkwürdigen Nachrichten von den inneren Theilen Neu-Spaniens und Reise aus Amerika bis in Deutschland).

Robles, Vito A. (notas)

1939 Relación del viaje que hizo a los Presidios Internos situados en la frontera de la América Septentrional perteneciente al rey de España. México: Pedro Robredo. (Documento original en la biblioteca de D. Pedro Robredo).

RuSSELL, Frank

1908 «The Pima Indians», en Twenty-Sixth Annual Report of the Bureau of American Ethnology (1904-1905), pp. 17-339. Washington: Smithsonian Institution.

SEGESSER, Felipe

1945 «The Relation of Philip Segesser: the Pimas and other Indians», Theodore Treutlein, trad. Mid America 27 (3): 139-187.

SPICER, Edward H.

1962 Cycles of Conquest. The Impact of Spain, Mexico and the United States on the Indians of the Southwest, 1533-1960. Tucson: University of Arizona Press.

VELARDE, Luis Javier

1977 «Las relaciones de la Pimería Alta, de Luis Xavier Velarde», en Etnología y misión en la Pimería Alta, 1715-1740, de Luis González R., pp. 27-122. México: Instituto de Investigaciones Históricas, Universidad Nacional Autónoma de México. (No se ha encontrado el original. El documento que se conserva es el que aparece insertado en los capítulos 9, 10 y 11 de la obra de Mange Luz de tierra incógnita, cuyo original se conserva en el Archivo General de la Nación en México, volumen 393, Historia, ff. 81v-92v). 